\title{
CENTRALIDADE DA GESTÃO DO ESTADO COMO LIMITE DA RAZÃO POLÍTICA OU PARA UMA CRÍTICA DA ADMINISTRAÇÃO POLÍTICA ${ }^{1}$
}

\author{
Elcemir Paço Cunha
}

http://dx.doi.org/10.1590/1413-2311.237.809126

\begin{abstract}
RESUMO
O artigo discute as considerações centrais da administração política sobre a gestão como objeto central. Argumenta-se que a centralidade da gestão para a administração política não a difere com relação ao chamado mainstream, mantendo a mesma redução dos problemas sociais a um mero problema de gestão. $\mathrm{O}$ artigo propõe uma retomada da relação entre a gestão do Estado e as contradições sociais, demonstrando que a gestão do Estado pressupõe e não procura eliminar tais contradições. Ao discutir a propositura da administração política de que seu objeto é a gestão, demonstra-se que o real objeto da gestão do Estado são as contradições sociais que formam sua base. Argumenta-se que, ao assumir o ponto de vista da gestão do Estado, a administração política fica implicada aos limites da razão política (voluntarismo político e impotência da administração), isto é, não apreende corretamente as forças motrizes das mazelas sociais. Propõe-se que administração política precisa expressar na realidade a relação entre Estado e o movimento contraditório da economia capitalista. Nesse sentido, apresentam-se ao final as implicações e os direcionamentos para a pesquisa na área.
\end{abstract}

Palavras-chave: Administração política. Contradições sociais. Economia capitalista.

\footnotetext{
${ }^{1}$ Recebido em 21/12/2018; aprovado em 22/06/2019.

${ }^{2}$ Universidade Federal de Juiz de Fora, Programa de Pós-Graduação em Administração, Juiz de Fora - MG (Brasil) - http://orcid.org/0000-0002-1978-0110. E-mail: paco.cunha@facc.ufjf.br.
} 


\title{
CENTRALITY OF STATE MANAGEMENT AS A LIMIT OF POLITICAL REASON OR TOWARD A CRITIQUE OF POLITICAL ADMINISTRATION
}

\begin{abstract}
The article discusses the central considerations of political administration about management as its central object. It is argued that the centrality of management to political administration does not differ from the so-called mainstream, while maintaining the same reduction of social problems as a mere management problem. The article proposes a resumption of the relationship between State management and social contradictions, demonstrating that the first one presupposes and does not seek to eliminate such contradictions. In discussing the proposition of political administration that its object is management, it is shown that the real object of State management are the social contradictions that form its basis. It is argued that in assuming the point of view of such management, political administration is implied to the limits of political reason (political voluntarism and impotence of the administration), that is, it does not correctly grasp the driving forces of social ills. It is proposed that political administration must express from reality the relationship between State and the contradictory movement of the capitalist economy. In this sense, we present at the end implications and guidelines for research in the area.
\end{abstract}

Keywords: Political administration. Social contradictions. Capitalist economy.

\section{CENTRALIDAD DE LA GESTIÓN DEL ESTADO COMO LÍMITE DE LA RAZÓN POLÍTICA O PARA UNA CRÍTICA DE LA ADMINISTRACIÓN POLÍTICA}

\section{RESUMEN}

El artículo discute las consideraciones centrales de la administración política sobre la gestión como objeto central. Se argumenta que la centralidad de la gestión para la administración política no la diferencia con el llamado mainstream, manteniendo la misma reducción de los problemas sociales a un mero problema de gestión. El artículo propone una reanudación de la relación entre la gestión del Estado y las contradicciones sociales, demostrando que la gestión del Estado presupone y no busca eliminar tales contradicciones. Al discutir la proposición de 
la administración política de que su objeto es la gestión, se demuestra que el real objeto de la gestión del Estado son las contradicciones sociales que forman su base. Se argumenta que, al asumir el punto de vista de la gestión del Estado, la administración política queda implicada en los límites de la razón política (voluntarismo político e impotencia de la administración), es decir, no aprehende correctamente las fuerzas motrices de las molestias sociales. Se propone que la administración política necesita expresar de la realidad la relación entre Estado y el movimiento contradictorio de la economía capitalista. En este sentido, se presentan al final implicaciones y direccionamientos para la investigación en el área.

Palabras clave: Administración política. Contradicciones sociales. Economía capitalista.

Ser radical é agarrar as coisas pela raiz.

K. Marx

\section{INTRODUÇÃO ${ }^{3}$}

É desnecessário dizer que domina na ampla área da administração - incluindo os aspectos formalistas da administração pública - tendências acríticas frente à realidade social. Por outro lado, os assim chamados estudos organizacionais, relacionados à ampla área da administração, são por natureza ecléticos e sem seta direcionadora. Ousaríamos dizer que segue como campo de pesquisa sem base racional, articulado fragilmente em torno de abstrações pouco úteis como "organização" (PAÇO CUNHA, 2010).

Diante desse quadro, a "administração política", como movimento intelectual de pesquisadores do nordeste brasileiro, sobretudo, é um sopro de lucidez. Por um lado, rechaça o acriticismo dominante na administração de maneira geral e certa miopia das avaliações de políticas públicas e, por outro lado, procura constituir uma delimitação própria em diálogos complexos com o pensamento social brasileiro, com a administração pública, com a economia política (keynesiana e neoclássica, sobretudo) e, em certa medida, com a crítica da

\footnotetext{
3 Agradecemos à Fundação de Amparo à Pesquisa do Estado de Minas Gerais (FAPEMIG) pelo apoio financeiro ao projeto que tornou possível o presente artigo.
} 
economia política e sua ascendência ao marxismo. Trata-se de um passo adiante, não resta dúvidas. Sua base racional está encaminhada precisamente no diálogo com a crítica da economia política embora não tenha sido, como veremos, inteiramente desenvolvida até o presente momento.

O movimento teórico da administração política pode ser entendido como o estabelecimento de um campo de conhecimento científico diferenciado na área da administração e, já galga audiência em variados periódicos e eventos nacionais. Procura fundar uma epistemologia própria para esta finalidade e recorre muito claramente à tradição sociológica do pensamento social brasileiro, como Guerreiro Ramos e João Ubaldo Ribeiro. Coloca em questionamento a visão instrumental da administração, exigindo consideração a respeito das particularidades nacionais, das necessidades da democracia política e do bem comum. É um movimento, portanto, imbuído da realização de uma análise reflexiva ao modo de regulação das relações sociais de produção por mediação do Estado e da empresa. Apesar disso, não configura como um movimento inteiramente homogêneo. Além das diferenças costumeiras em razão de predileções dos autores, é mais importante o debate interno entre os principais proponentes do movimento e a corrente marxista, minoritária, na qual se inclui o presente artigo (JUSTEN et al., 2017).

Com respeito ao problema específico e motivador deste ensaio, podemos extrair o traçado basilar do movimento da administração política a partir de alguns dos seus principais proponentes, conforme publicação mais recente. A administração política é apresentada em geral como um campo de pesquisa, tendo a gestão como objeto que o instrui. Logo de partida, fica demarcada a centralidade da gestão para o movimento. A angulação dessa gestão é o Estado, constituindo propriamente a "esfera da administração política" de "políticas públicas + planejamento"4 (SANTOS et al., 2017, p. 944). Delimitada em reciprocidade com a economia política, "cabe à administração política responder ao desafio, não menos importante, de conceber formas de gestar e gerenciar" a concepção socioeconômica determinada por aquela. De tal modo, “à administração política incumbe, portanto, conceber (gestar) e fazer (gerenciar/operacionalizar) os meios para garantir a condução das possibilidades (ideais, reais e potenciais) de produção, circulação/realização e distribuição, com vistas a elevar o nível de materialidade individual e social e garantir, desse modo, a sustentabilidade e reprodução do sistema socioeconômico" (SANTOS, 2017 et al., p. 948). Uma vez que, para esta corrente, o Estado ganhou protagonismo como "executor e planejador

\footnotetext{
${ }^{4}$ A inserção do conceito "administração profissional" (cf. SANTOS et al., 2017), para designar a gestão das unidades produtivas, em nada altera a delimitação da administração política à esfera do Estado.
}

REAd | Porto Alegre - Vol. 25 - No 2 - Maio / Agosto 2019 - p. 150-178 
de políticas públicas, constituindo o principal empreendedor individual do capitalismo e assumindo, desse modo, a condição de principal capitalista a comandar capitais", é possível dizer, assim, que o "poder público passa a refletir a essência da definição de administração política" (SANTOS, 2017 et al. p. 949). O Estado é o agente encarregado de dar movimento a um "modo de concepção e execução de projeto de nação", isto é, a "busca da finalidade última da vida social, materializada no alcance do bem-estar" (SANTOS, 2017 et al., p. 948). É deste modo que o "Estado atuaria como receptor das demandas/necessidades sociais coletivas e assumiria, assim, o papel de definidor das prioridades e temporalidades (teórica e administrativa) para a execução do projeto de nação" (SANTOS, 2017 et al. p. 949).

O presente ensaio discute algumas considerações nucleares da administração política sobre a gestão do Estado na qualidade de objeto central de sua efetivação como campo de estudos, procurando direcionar esse delineamento para uma crítica fundada no materialismo que angula a crítica da economia política de ascendência marxista. Não é do interesse no momento a discussão de uma programática política e sim o problema científico de determinar aquilo que é e como funciona.

Nosso argumento é que tomando a gestão como centralidade, o movimento da administração política não rompe com os limites da razão política, razão que não apreende as forças motrizes de ordem primária na determinação das mazelas sociais que supõe combater. Pretendemos demonstrar em maiores detalhes que o prevalecente entendimento equivocado, sempre implícito e não tematizado diretamente - do Estado como ente moral e supraclasses sociais prejudica uma reta apreensão dos nexos efetivos entre o próprio Estado e as contradições sociais ${ }^{5}$. Sobretudo, no que toca à relação entre Estado e tais contradições (entre elas o capital como contradição em processo), essa corrente assume a reprodução viciada por meio do Estado como virtude, imaginando que este regula o principal e autêntico regulador do sistema quando é, em verdade, efetivamente regulado: o grande capital e suas formas.

Nesse sentido, primeiro apresentamos a centralidade da gestão para a administração política a partir de algumas elaborações essenciais, produzidas desde 1993. O objetivo é

\footnotetext{
${ }^{5}$ Não é o bastante afirmar que o Estado não é "externo às relações sociais de produção" ou que é o "principal capitalista a comandar capitais" (SANTOS et al., 2016, p. 1013), para, em seguida, fazer uma apologia ao Estado capitalista do pós-segunda guerra mundial, concluindo que dos anos de $1970 \mathrm{em}$ diante o "Estado capitalista perdeu enorme capacidade de coordenação e esse fato tem levado à desorganização das relações sociais de produção e distribuição - tem levado ao aprofundamento da crise" (SANTOS el al. 2016, p. 1026). Nunca fica revelado o caráter classista do Estado à serviço contraditoriamente da lógica do capital social total (produtivo, financeiro, comercial e não apenas do rentismo, ver em: SANTOS, 2016 et al., p. 1026, para uma clara fixação nesta última forma keynesianamente considerada por rentismo).
} 
mostrar que nesse quesito a administração política não se distingue do mainstream quanto se supõe e aceita o operatório que reduz os problemas sociais à gestão, isto é, a gestão como solução para tais problemas. Com isso, deixa-se de revelar a questão mais decisiva de se explicitar a relação entre a gestão do Estado e as contradições sociais pelo motivo de que a administração política é uma "razão interessada", um ponto de vista interessado e por isso ideológico $^{6}$ (JUSTEN et al., 2017, p. 707-713), da própria gestão do Estado - em seus devidos termos, determinado como expressão das contradições sociais.

Em seguida, retomaremos as considerações de Marx sobre a relação entre o Estado e o pauperismo, sobretudo, na Inglaterra do século XIX, para indicar a análise de realidade dos casos concretos evocados adiante do Brasil, Estados Unidos e Suécia no século XXI. O objetivo é mostrar, a partir da realidade de séculos diferentes, e não da mera exaltação do autor mencionado - que aliás, dispensa honrarias -, os limites reais imanentes à gestão do Estado capitalista por meio de medidas administrativas ("políticas públicas + planejamento") e os limites do entendimento político daí derivado. Insistimos: o recurso ao autor é mediação para sublinhar uma relação objetiva entre Estado, sua gestão e as contradições sociais que marcam a dinâmica do modo de produção capitalista. Apontaremos para as determinações objetivas que mostram que o Estado capitalista não visa a e nem pode superar as contradições que formam sua base.

Por fim, tomaremos as variadas considerações para explorar algumas implicações para a administração política que pretende romper com o entendimento político e adquirir uma fundamentação materialista, determinando as contradições sociais como o efetivo objeto da gestão do Estado. Assim, a administração política pode expressar corretamente relações reais entre o Estado (com suas respostas administrativas) e as contradições sociais que emanam da base econômica uma vez que, materialmente apreendido, o fundo das coisas é relação.

\section{CENTRALIDADE DA GESTÃo PARA O MOVIMENTO DA ADMINISTRAÇÃO POLÍTICA}

À primeira vista é uma obviedade constatar que a gestão ocupa lugar central para a administração como área de pesquisa. Mas existem mais coisas nessa centralidade que revelam os limites de apreensão da realidade ao assumir uma posição centrada em si mesma,

\footnotetext{
${ }^{6}$ Assumimos que não há contradição entre razão interessada e possibilidade científica (GUEDES, 2015). Toda razão é interessada e, por isso, ideologia de uma posição social particular, guardando variado potencial científico. Guardamos a acepção de ideologia aqui nesse sentido mais restrito, de formação ideal correspondente a uma posição social, e longe da tradicional conotação de falsidade, ilusão, erro ou malogro.
}

REAd | Porto Alegre - Vol. 25 - No 2 - Maio / Agosto 2019 - p. 150-178 
não radical, que não "agarra as coisas pela raiz"7. Além do mais, se a gestão ganha centralidade, é preciso perguntar como se expressam as contradições sociais uma vez que a administração política como corrente teórica reivindica um deslocamento em relação ao mainstream que notoriamente é avesso em seu caráter acrítico à evocação de tais contradições. A bem da verdade, para o mainstream tais contradições sequer existem na exata medida em que é negada a existência das classes sociais.

Tomando a administração política como um passo adiante com relação ao mainstream, precisaremos perguntar sobre a relação entre gestão do Estado e as contradições sociais, relação que a administração política precisa explicitar de suas próprias entrelinhas. Mas vejamos primeiro como esta corrente insinua essa relação, embora tome por central a gestão ao invés das próprias contradições em relação ao Estado.

Essa centralidade, para o chamado mainstream, é mais do que uma determinação de objeto de estudo como tende a ser para a administração política. Afinal, não é novidade o interesse no estudo da prática administrativa no intuito de aprimorar a "eficácia organizacional" - e é dispensável dizer que todo o movimento do pensamento administrativo propriamente dito responde ao problema da produtividade do trabalho nas diferentes fases de desenvolvimento do capitalismo ${ }^{8}$. O curioso é aquilo que vai além desse interesse e que coincide com uma absoluta apologia, além da promoção de uma espécie de redução dos complexos problemas sociais à própria gestão. Em suma, trata-se de uma centralidade da gestão mesmo para a administração marcadamente pertencente ao mainstream; algo que, portanto, não serve para a distinguir frente à corrente da administração política.

Podemos chamar a atenção para um exemplo, em que Peter Drucker consegue aglutinar tanto a apologia quanto a redução. Num artigo muito conhecido do público brasileiro, o austríaco comenta que "a administração tem sido a atividade vitoriosa por excelência nestes últimos cinquenta anos - mais até do que a ciência" (DRUCKER, 1986, p. 7). Frise-se: "mais até do que a ciência". Avalia a administração na qualidade de mediação

\footnotetext{
${ }^{7}$ Aqui, de partida, está a morada do evidente problema de realizar projeções. Pelo fato de ser uma produção intelectual que parte da administração como área, é constante o assédio de se fixar na própria "administração" como uma decisiva mediação, concedendo potências superestimadas.

${ }^{8}$ Pensamento administrativo tem aqui pretensão limitada. Não envolve as tradições sociológicas nem as tendências críticas que se debruçaram sobre a explicação da função de direção na produção do capital, por exemplo. De alusão restrita, envolve o pensamento direta ou indiretamente apologético. Sem volteios, "basta a apreensão do pensamento administrativo como uma formação ideal de interesses materiais determinados. (...) trata-se da transposição da finalidade do capital para a forma teórica: expressão ideal de interesses materiais dominantes sem necessariamente formar uma unidade intelectual linear, uma vez que comporta diferenças em seu interior, desacordos e discussões duradouras, mesmo entre os homens práticos e seus representantes teóricos nas escolas de negócio" (PAÇO CUNHA; GUEDES, 2017, p. 436).
} 
potencial e não contraditória para a realização dos fins comuns, ao afirmar que "a administração precisa tornar-se o instrumento pelo qual a diversidade cultural possa atender às finalidades comuns da humanidade" (DRUCKER, 1986, p. 18). Além da apologia aberta e sem disfarces, intui ser portador de exagero embora ignore a própria intuição: "pode-se dizer, sem muito exagero de simplificação, que não existem países subdesenvolvidos. Existem apenas países subadministrados"9 (DRUCKER, 1986, p. 19, itálico no original). Todo o complexo de problemas envolvido no "desenvolvimento nacional" é para ele redutível, ao modo como as coisas são enfim administradas, pois "toda a nossa experiência em desenvolvimento econômico prova que a administração é o principal propulsor e que o desenvolvimento é uma consequência" (DRUCKER, 1986, p. 20). Vê-se que todos os problemas sociais são reduzidos à administração, à gestão. Saem de cena as contradições sociais e a administração aparece como a potência resolutiva.

Por qual motivo podemos encontrar semelhante movimento nas principais elaborações da administração política? Evidentemente não se trata da mesma e exata questão. Basta saber que existe nesta corrente, de maneira totalmente aberta e declarada, uma propositura distinta do chamado mainstream. Sua demarcação segue pelo caminho do "fazer ciência da administração" e pela ampliação da consciência frente aos problemas a serem enfrentados. Não se questiona as efetivas potencialidades da própria gestão. Entretanto, fica presumida a gestão como força maior, no mesmo talhe da linha frente a qual pretende se diferenciar:

Evidentemente que outros espaços de fazer ciência da administração surgiram nas últimas duas décadas, pelo menos. Isto de certa maneira vem "furando o cerco" da hegemonia do mainstream, principalmente de origem anglo-saxã. É crescente a consciência política e científica de que os fenômenos sociais, a dinâmica econômica, com manifestações de crises periódicas, e a dinâmica ambiental, exigem, também, da ciência da administração uma capacidade de respostas, científica e técnica, para que a humanidade enfrente os desafios impostos pela degradação social e da natureza que o regime de produção continua a impor (GOMES, 2012, p. 8).

Pressuposta como capaz de dar tais respostas resolutivas, a semelhança com o próprio mainstream do qual se pretende distanciar não é pouco visível. Essa redução das contradições

\footnotetext{
9 “A América Latina não é subdesenvolvida, é suborganizada" (DRUCKER, 1975, p. 42), escreveu o autor em outro lugar. O autor austríaco, no entanto, atribui a expressão a um intelectual latino americano professando sobre seu continente, mas não o identifica.
} 
à gestão pode ser reforçada por outros aspectos que revelam que a presumida ruptura com o mainstream se dá num plano meramente conceitual e, termina por enfatizar a mesma finalidade comum abstratamente posta tal como as "finalidades comuns da humanidade" anteriormente registradas por meio da pena de Drucker:

A compreensão dessa ruptura instrumentalista deve ser um dos fundamentos básicos dos pressupostos da administração política. Então, as interfaces entre as relações das razões instrumentais e subjetivas constituem (...) um pressuposto básico da estruturação da Administração Política para privilegiar um plano nacional com fins societais de desenvolvimento humano comum (SANTOS, 2009, p. 77).

Há que se enfatizar novamente que a ruptura é dada no plano conceitual, adicionando uma "razão subjetiva" à "instrumental" - uma saída reconhecidamente sociológica e parentética - e tomando isso por autêntica ruptura. Não obstante, é possível afirmar um "desenvolvimento humano comum" apenas de maneira abstrata e sem lastro real na medida em que saem de cena as contradições sociais e as classes operantes. Ora, como é possível um desenvolvimento desta natureza pressupondo existente uma sociabilidade com uma distribuição dos meios de produção da riqueza que põe e repõe as condições para a negação do próprio "desenvolvimento humano comum", uma sociabilidade cuja lógica é a acumulação privada e que não sucumbe às nossas conjecturas e vontades?

$\mathrm{Na}$ consideração crítica do mainstream, acusado de "conceber a gestão como um fim em sim mesmo", a administração política se coloca noutra direção, requerendo que a gestão seja "um meio para se alcançar resultados materiais em uma sociedade mais igualitária"10 (GOMES, 2012, p. 17-8). Poder-se-ia fazer essa exigência da administração? Teria ela essa potência aqui pressuposta? Com a diferença de que esse sentido "igualitário" esteja ausentado do mainstream, mantem-se pressuposta a gestão como mediação central da realidade, seja

\footnotetext{
${ }^{10}$ A tônica se mantém, anos mais tarde, quando se lê que é "essencial, assim, que a administração, enquanto campo de reflexão e prática (práxis) humana, afaste-se do engajamento ideológico automático - manifesto nos princípios do imediatismo dos resultados econômicos - para se pronunciar, criticamente, em relação aos processos sociais estabelecidos de modo a propor alternativas para que parcela expressiva da sociedade/humanidade se liberte da necessidade de trabalhar até o último minuto de sua existência para ter a oportunidade de garantir uma materialidade mínima (sobrevivência) que garanta uma sobrevivência digna" (SANTOS et al., 2017, p. 946, grifos nossos). Se uma parcela da sociedade ainda permanece escrava da necessidade de trabalhar por óbvio que testemunhamos a permanência de classes sociais, do antagonismo de classe e, logo, da exploração econômica do trabalho. Melhor seria pôr como horizonte a redução absoluta do tempo de trabalho de todos ao mínimo possível para que os indivíduos possam se desenvolver autenticamente sem exploração econômica dos homens entre si.
} 
como verdadeira força motriz para o desenvolvimento econômico, seja como mediação para uma "sociedade igualitária".

Destaquemos ainda mais essa centralidade da gestão para a corrente administração política, pois nos ajuda a revelar a posição social de sua propositura, sua razão interessada enquanto ideologia particular (JUSTEN et al., 2017). Fazendo eco com as linhas apresentadas antes na introdução, podemos ler que há uma 'valorização da 'gestão' como categoria essencial da administração" e que essa centralidade permite revelar o verdadeiro "objeto de estudo da administração como campo do conhecimento" (GOMES, 2012, p. 11). Sem volteios, "a gestão constitui-se no objeto próprio da administração política" (SANTOS, 2009, p. 61). Trata-se, pois, da "forma pela qual o Estado se organiza e se estrutura para gerir [e gere] o processo das relações sociais de produção" (SANTOS; RIBEIRO, 1993, p. 106). Em outros termos, importa a gestão estatal das relações de produção, do Estado como o demiurgo da sociedade.

É preciso esclarecer tais "relações sociais de produção". Ora, não estão aí como constitutivos a divisão da propriedade dos meios de produção, o relacionamento entre capital e trabalho, o movimento contraditório da produção do valor e, portanto, os mecanismos para a acumulação privada da riqueza e a consequente ampliação da desigualdade social apesar do progressivo aumento das forças produtivas? É inegável que se trata da questão levantada antes acerca da relação entre a gestão do Estado e as contradições sociais. E é precisamente essa relação que não parece estar totalmente consciente para a própria propositura científica de uma administração política ao manter a gestão como sua centralidade.

Como existem aqui muitas questões importantes, retomaremos certos aspetos no próximo item. Retemos nesse momento somente a insuficiência em revelar o verdadeiro ângulo da análise proveniente da própria administração política. Trata-se em parte de um sujeito oculto - embora já revelado em nossa introdução. É possível desvelá-lo uma vez mais: [...] fica evidente que a economia, particularmente a economia capitalista, é operada, de forma deliberada, por um processo gestionário. É algo como se O Que Fazer (tomado aqui como a definição das quantidades) nunca pudesse se viabilizar sem $O$ Como Fazer (compreendido como sendo os arranjos organizacionais e institucionais necessários para viabilizar a produção das quantidades demandadas). Esse é o momento em que a Economia Política caminha junto da Administração Política - portanto é o momento em que se compreende de forma científica que a produção, a sua 
realização e a sua distribuição não se efetivam em termos de resultados ótimos sem uma concepção de gestão previamente estabelecida (SANTOS, 2009, p. 90).

Fica dito o que precisa ser feito ("operar a economia capitalista", na "definição das quantidades"), o como pode ser feito (“arranjos organizacionais e institucionais"), mas quem deve fazer não se explicita abertamente embora já saibamos ser o Estado. Tendo, portanto, o Estado por tal sujeito, torna-se revelado o ponto de vista da administração política:

Os autores [SANTOS; RIBEIRO, 1993], portanto, tiveram o mérito de romper com a hegemonia das análises economicistas e da crítica da economia política. Avaliaram a perspectiva histórica com um olhar que resgata a importância da administração como campo da ciência social também preocupada em construir a crítica de seu ponto de vista, ou melhor, do ponto de vista da administração política. Uma crítica que se debruça sobre os aspectos essenciais da gestão das relações em uma sociedade capitalista periférica e subalterna no jogo de poder internacional. Portanto, estava dado o "pontapé inicial" do longo caminho metodológico-conceitual com a finalidade de desenvolver o conceito de administração política com base nas transformações que afligiam, sobretudo, o Estado, as relações de produção e o processo de acumulação (GOMES, 2012, p. 12).

A alegada ruptura com a crítica da economia política já é anúncio de uma posição social de resignação frente o necessário processo de transformação para alguma "sociedade mais igualitária", como é aparentemente pretendido. É preciso reter, não obstante, que está em jogo o ponto de vista do Estado capitalista e que o fator preponderante deste ponto de vista é a própria gestão do Estado. Tudo se esclarece como segue:

De logo, é importante precisar melhor o conceito de administração política que deve ser compreendido no âmbito das relações sociais que se estabelecem para a estruturação de formas de gestão da sociedade. Considerando que o Estado é o árbitro dos sistemas de controle sociais (leis, normas, regulamentos etc.), então a gestão social (ou seja, a administração política) termina por ganhar mais densidade no âmbito do Estado, portanto, nas relações do Estado com a sociedade. Nesse caso, podemos dizer que a administração política é a concepção de um modelo de gestão das relações socais que tem 
por objetivo garantir certo nível de bem-estar, expresso nas garantias plenas da materialidade (SANTOS, 2009, p. 37, nota 4, grifos nossos).

Vê-se que, tomando o Estado como demiurgo, o objeto é a gestão do Estado e não as contradições sociais que a informam, isto é, sua relação, movimento e contradição frente a própria atuação estatal. Assim, a administração política precisa explicar, então, o suposto interesse de um Estado capitalista em uma "sociedade mais igualitária", como dito antes, ou em um "certo nível de bem-estar", agora de modo mais brando, sem processos transformadores agudos e revelar as possibilidades reais nesses termos ou terá que assumir que se trata apenas de uma forma diferenciada, posta como um "dever ser" abstratamente determinado por vontade política, de organizar a mesma produção do valor que engendra as contradições que confrontam o Estado nessa elaboração da administração política (veremos adiante que esse "confronto" é, ao mesmo tempo, pressupor tais contradições existentes sem superá-las). Um "modelo de gestão das relações sociais", como dito na passagem acima, explicita o interesse político-burocrático de administrar os homens sem alterar as próprias relações entre eles.

Há o pressuposto de ser a gestão do Estado o sujeito capaz de administrar o capital, humanizá-lo, discipliná-lo, tendo em mira uma "sociedade mais igualitária”, de "certo nível de bem-estar" e que mantém, no entanto, as condições da própria desigualdade que se pretende combater. Há, igualmente, o pressuposto do Estado como ente não contraditório, portador racional dos interesses comuns. A administração política, frente a esses problemas práticos, precisa explicar a si mesma ao revelar a relação entre a gestão do Estado e as contradições sociais, incluindo aí as classes sociais. Ora, trata-se de um Estado racional, não contraditório, supraclasses? Afinal, o que é o Estado capitalista em suas reais determinações?

Tudo indica haver na propositura da administração política uma intenção de mudança em coexistência com a centralidade da gestão. Vê-se isso nos próprios termos empregados, pois além da "sociedade mais igualitária", "certo nível de bem-estar" - lembrando em parte os apelos do sansimonismo do século XIX -, é possível constatar que numa dada sociedade capitalista "o que temos é uma administração política voltada para os interesses da base econômica sob o domínio do capital", de modo que "as necessidades reais da sociedade ficam em segundo plano, subsumidas aos interesses do capital” (GOMES, 2012, p. 17). Se é audível uma crítica da economia política, a mudança parece não transcender a intencionalidade e nem o plano meramente conceitual, como já aludido (o que é afinal a sociedade?). Fica sugerido um tipo particular de sincretismo visando acomodar as contradições sociais ao invés de 
resolvê-las. Como veremos, a centralidade da gestão é índice desse problema. Ora, e o que é a gestão do Estado senão uma dada ação por meio dos aparatos administrativos, jurídicos e militares sobre as contradições e, portanto, uma manifestação de supremacia na correlação de forças entre frações de classe sobre tal gestão estatal?

Em suma, não obstante a posição científica muito mais avançada do que suas contrapartes tradicionais (administração instrumental e estudos organizacionais), parece existir na administração política uma apologia ligeiramente diferenciada, mas em termos muito assemelhados àquela encontrada no mainstream que ela própria pretende combater: de ser a capacidade administrativa do Estado, a potência necessária e suficiente ao enfrentamento das mazelas sociais. Essa apologia é simultânea à redução das contradições e complexos sociais à gestão do Estado. É nesse sentido que a centralidade da gestão para a administração política é índice desse pressuposto basilar, mas não inteiramente tornado consciente pelas principais proposituras científicas desta corrente.

Assim, a relação entre a gestão do Estado e as contradições sociais precisa ser trazida totalmente à baila sob pena de se eliminar da análise as classes sociais e as frações de classe, isto é, a manifestação das contradições no plano econômico e político. É o que pretendemos desenvolver a seguir.

\section{LIMITES DA RAZÃO POLÍTICA E DA GESTÃo DO ESTADO}

A corrente teórica que temos acompanhado paga um pesado tributo a grande parte da tradição ocidental quando o assunto é o Estado. Com a tendência de tomá-lo como ente não contraditório e de ser expressão do ponto de vista do Estado, deixa de revelar a relação do Estado com as classes sociais ${ }^{11}$. O Estado, então, assume feições monolíticas e morais, sem

\footnotetext{
${ }^{11}$ É preciso enfatizar que isso se confirma tendencialmente haja vista a existência de outras elaborações que apontam que "o conceito de Administração Política resgata tradições clássicas do pensamento crítico ao mesmo tempo que questiona o paradigma referendado acerca da "neutralidade", da supremacia da "técnica" e dos objetivos "consensuais" do Estado. Afinal, o Estado não é neutro - dado que, reitere-se, está a serviço da reprodução da sociedade de classes -, é constrangido pela lógica da acumulação capitalista, que é mutável e inclui necessariamente o contexto internacional, e seus objetivos (do Estado) são contraditórios em razão da própria contradição da sociedade de classes à qual sua existência é condicionada" (FONSECA, 2008, p. 9). Veja também considerações menos determinadas sobre as classes em Santos et al. (2016). Ocorre, porém, que essa tendência em marcar a relação entre as classes, o Estado e a lógica do valor de modo consequente é algo mais marginal no conjunto das principais formulações, havendo uma tendência mais forte para se tomar as necessidades individuais e o Estado como receptor de demandas. O capital e o trabalho como classes, por exemplo, são tendencialmente evanescências (SANTOS et al., 2016). É possível investigar se essas oscilações não são fruto de um estágio de desenvolvimento da discussão em que não ficou totalmente esclarecida a
}

REAd | Porto Alegre - Vol. 25 - No 2 - Maio / Agosto 2019 - p. 150-178 
fissuras e acima das classes sociais. Daí decorre, por exemplo, a ideologia da burocracia de Estado como um aparato meramente técnico, apartidário e sem relação com interesses das classes. Em suma, a "classe universal" de Hegel (2010), a qual alegadamente cuida do “interesse geral” (MARX, 2005).

É a luta política, no entanto, entre as classes e as frações de classe que molda a própria gestão do Estado. E claro, existe a reciprocidade: que um dado modo de gestão pode dar certo rumo a tais contradições e antagonismos - sem, no entanto, resolvê-los, como veremos a seguir. A clássica afirmação de que "o executivo no Estado moderno não é senão um comitê para gerir os negócios comuns de toda a classe burguesa" (MARX; ENGELS, 1998, p. 42), não contradiz a correlação de forças entre as frações moldando a gestão do Estado uma vez que as frações dominantes da classe dos proprietários do capital (incluindo os gestores econômicos e políticos do capital) (PAÇO CUNHA; JORGE, 2018) tendem a imprimir seus interesses dada a sua supremacia, mas não sem alianças e sem a acomodação das classes dominadas, nem sem conflitos internos às próprias classes dominantes ${ }^{12}$.

Não obstante certo formalismo lógico, Poulantzas (1980) conseguiu expressar muito bem esse problema, da luta de classes e das frações de classe no interior do próprio Estado, incluindo seu aparato burocrático. Mas é preciso evitar soluções esquemáticas que apelam excessivamente para modelos gerais. Por isso, podemos considerar o problema tal qual Lukács (2013) tematizou brevemente acerca do direito, mas que é facilmente apreensível

diferença entre a administração política e a crítica da administração política, sendo esta última o caminho delineado também pelo presente artigo.

${ }^{12}$ Igualmente, não contradiz o fato de que o Estado realiza também funções, por assim dizer, "comunitárias". A propósito da atividade de supervisão e em polêmica com a confusão entre lucro e salário de superintendência, Marx considerou que o trabalho de "supervisão necessariamente surge nos modos de produção que repousam sobre o antagonismo entre o trabalhador como produtor direto e o proprietário dos meios de produção. Quanto maior é esse antagonismo, maior é o papel desempenhado pela supervisão. Por isso, ela atinge seu auge no sistema escravista. Ela também é imprescindível no modo de produção capitalista, uma vez que nele o processo de produção é, ao mesmo tempo, um processo de consumo da força de trabalho pelos capitalistas. Exatamente como nos Estados despóticos, o trabalho de supervisão e a intervenção do governo envolvem tanto a realização de atividades comuns, que derivam da natureza de todas as comunidades, quanto as funções específicas decorrentes do antagonismo entre o governo e a massa popular" (MARX, 2017, p. 433). Há funções derivadas das necessidades comuns (controle de epidemias, por exemplo) e há funções (administrativas e repressivas, como veremos adiante) derivadas de antagonismos que se expressam na relação entre Estado e vastas cadeias de classes sociais. Essa coexistência de funções não altera o fato de o Estado funcionar como o interesse coletivo do capital. Ao contrário, o entrelaçamento entre essas funções é algo que ajuda a, por um lado, evitar que se explicite o caráter de dominação e, por outro, direcionar o conflito para o plano político, administrativo, militar e jurídico ao invés de se resolver no plano econômico pelo embate direto entre as classes. Os teóricos da administração política conseguem apreender o Estado como gerente do capital, mas não extrair todas as consequências disso, isto é, porquanto gerente, sabe reconhecer o seu mestre a quem personifica e realiza suas funções em seu nome.

REAd | Porto Alegre - Vol. 25 - No 2 - Maio / Agosto 2019 - p. 150-178 
como um problema da "oficialidade" estatal com o intuito de indicar a questão dos antagonismos mais complexos:

Em primeiro lugar, muitas sociedades de classes estão diferenciadas em várias classes com interesses divergentes, e não ocorre com muita frequência que a classe dominante consiga impor em forma de lei seus interesses particulares de modo totalmente ilimitado. Para poder dominar em condições otimizadas, ela precisa levar em conta as respectivas circunstâncias externas e internas e, na instituição da lei, firmar os mais diferentes tipos de compromissos. Está claro que sua extensão e magnitude exercem influência considerável sobre o comportamento das classes que deles participam, positiva ou negativamente. Em segundo lugar, o interesse de classe nas classes singulares é, na perspectiva histórica, relativamente unitário, mas em suas realizações imediatas ele muitas vezes apresenta possibilidades divergentes e, mais ainda, avaliações divergentes por parte das pessoas singulares envolvidas, razão pela qual, em muitos casos, a reação à legislação e à jurisdição não tem de ser unitária nem dentro da mesma classe. Isso se refere, em terceiro lugar, não só às medidas que uma classe dominante adota contra os oprimidos, mas também à própria classe dominante (sem falar de situações em que várias classes participam da dominação, por exemplo latifundiários e capitalistas na Inglaterra após a "Glorious Revolution" [Revolução Gloriosa]). Abstraindo totalmente das diferenças entre os interesses imediatos do momento e os interesses em uma perspectiva mais ampla, o interesse total de uma classe não consiste simplesmente na sumarização dos interesses singulares dos seus membros, dos estratos e grupos abrangidos por ela. A imposição inescrupulosa dos interesses globais da classe dominante pode muito bem entrar em contradição com muitos interesses de integrantes da mesma classe (LUKÁCS, 2013, p. 233).

Apreendendo então que no interior do próprio Estado se manifestam os conflitos mais complexos entre as classes, passa a ser decisivo compreender as relações de força e, nelas, a supremacia de frações de classe e suas alianças. Nesse sentido, a administração política, como ponto de vista do Estado, é posição social na correlação de forças que molda essa 
gestão do Estado, o modo de funcionamento dos aparatos administrativos, jurídicos e militares os quais, por sua vez, porquanto formam também camadas sociais nada desprezíveis - ou "estamentos ideológicos", como governo, clero, juristas, militares etc." (MARX, 2013, p. 518) -, desenvolvem interesses sociais e realizam alianças com as frações de classe na luta política.

Ora, a quem serve a administração política enquanto ideologia, expressão dessa posição social, enquanto razão interessada?

Como vimos antes, tomada a gestão como o elemento decisivo, não menos importante é, no entanto, a dimensão das relações sociais de produção. No interior dessas relações persistem contradições e antagonismos, sem dúvida, não apenas aquele que demarca no âmago a produção do valor, mas contradições inclusive entre as frações de classe no interior das próprias classes sociais, como aludido acima, seguindo Lukács (2013). Então, ao invés de situar, como faz a administração política, como objeto o modo como o Estado se organiza para gerir e gere tais relações, seria mais essencial perguntar: como o Estado se relaciona com tais contradições sociais? É esta a questão que precisa vir à baila.

Trata-se de uma questão fundamental para a qual a gestão do Estado é uma parte da resposta. Poderíamos dizer que esse é também o limite da administração política ao não apreender as contradições em meio às quais está a própria gestão incluída como o objeto central. A categoria essencial da gestão do Estado, a esfera própria da administração política colocada em seus termos corretos não é, portanto, a gestão do Estado, mas as contradições sociais em "oposição" à gestão do Estado. Limitando-se à gestão do Estado como angulação da realidade, perde-se de vista precisamente a real função deste e a relação de seu aparato administrativo, jurídico e militar frente às classes sociais e destas com respeito às contradições operantes da base econômica.

A maneira mais segura é tomar, da realidade concreta, o modo como os Estados mais desenvolvidos e os periféricos são geridos frente as contradições sociais. Com isso conseguimos identificar também a relação da gestão do Estado com tais contradições.

O que revelam os casos concretos, por exemplo, dos Estados Unidos da América ou da Suécia? Para que seja possível uma rápida apreciação, tomemos o exemplo da desigualdade de renda como uma expressão mais visível das contradições de fundo, sobretudo, a distribuição dos meios de produção da riqueza - quer dizer, a sociedade que mais avançou a produção socializada de riquezas também é a que produz elevado nível de apropriação privada dessa mesma riqueza. Como lidam com a desigualdade nesses países de economia avançada? Ambos se relacionam por meio de, grife-se, medidas administrativas 
(“políticas públicas+planejamento”) de ordem repressiva e assistencial, além de outras medidas de natureza assemelhada ${ }^{13}$. Uma rápida observação aos órgãos desses países comprova o enunciado ${ }^{14}$. Mas, mesmo nesses países a desigualdade tem demonstrado tendência de crescimento, como atesta a pesquisa de Piketty (2014) sobre a concentração da riqueza e a queda geral dos salários. E no Brasil, encontramos algo diferente? As mesmas medidas administrativas podem ser encontradas na atuação do Estado frente aos problemas sociais, em particular a desigualdade social. Alguns programas, como o Bolsa Família, materializam políticas semelhantes das encontradas em terras nórdicas ou estadunidenses e que não ultrapassam o momento da circulação, do mercado de consumo, privilegiando, inclusive, o endividamento familiar. Quem poderia afirmar que isso não é a procura por um "certo nível de bem-estar"?

Porém, é preciso perguntar: em algum desses países a desigualdade social foi eliminada? Não. E qualquer avanço nessa direção é constantemente ameaçado pelo movimento próprio da economia capitalista, resultando em crises e em regressões sociais notáveis. Não é e nem pode ser objetivo do Estado capitalista e de sua gestão a superação da desigualdade social e é aqui que a administração política precisa questionar seus pressupostos acerca do interesse do Estado e da potência de sua atuação administrativa em meio à relação das classes sociais e as contradições ao fundo.

A potência imanente das medidas administrativas do Estado foi magistralmente exposta por Marx nas Glosas críticas de 1844 e a ela devemos recorrer para, no esforço de síntese, apreciar os limites da administração política como expressão dos limites da gestão do próprio Estado capitalista. Em outras palavras, trata-se de demonstrar objetivamente os limites da ação estatal por meio de medidas administrativas frente às contradições sociais. Ao fazer isso, ficará evidente que o esforço de gerir - com potência variada e contingente - as contradições sociais, não é o mesmo que as abolir. De tal forma, vai se demonstrando que o objeto real da administração política são as contradições sociais que formam a base material do Estado.

Em tais glosas, Marx enfrenta a tese de Arnold Ruge, qual seja, a de que o rei da Prússia implementou medidas administrativas e assistencialistas para combater o pauperismo

\footnotetext{
${ }^{13}$ Convém deixar apontado que a relação entre medidas repressivas e medidas administrativas é destaque do movimento da forma política sempre em resposta aos problemas práticos impostos pela dinâmica econômica e social, portanto, classista. Para detalhes sobre esse movimento para os casos da Inglaterra, França e Alemanha do século XIX, consultar Paço Cunha (2017).

14 Disponível em: https://www.usa.gov/benefits-grants-loans. Acesso em: 16 jul. 2019; disponível em: http://www.government.se/government-policy/social-care/ Acesso em: 16 jul. 2019.
}

REAd | Porto Alegre - Vol. 25 - No 2 - Maio / Agosto 2019 - p. 150-178 
e toma a administração precisamente como fonte de falhas em razão de ser a sociedade alemã apolítica, por não possuir um entendimento político desenvolvido da questão ${ }^{15}$. Assim, a sociedade alemã não detecta a "penúria dos distritos fabris como um problema universal", nas palavras de Ruge (MARX, 2010, p. 25-26), por ser um país apolítico.

Marx procura mostrar, em interdição à tese de Ruge, que a implementação de medidas administrativas e a atribuição de falhas a elas é um dos resultados comuns da ação política, pois a "administração é a atividade organizadora do Estado" (MARX, 2010, p. 39). Insiste que a implementação de medidas administrativas é impotente para a resolução das "mazelas sociais" e que quanto maior for o entendimento político, menos se reconhecem quais são de fato as causas dos problemas sociais enfrentados. Vejamos essas questões mais de perto.

As constatações objetivas são retiradas da análise dos casos concretos da Inglaterra, principalmente, mas também da França e da Alemanha, nos quais a questão decisiva é determinar o nexo objetivo entre o pauperismo e os Estados nacionais. Limitando-nos ao caso inglês, Marx (2010, p. 30) sugere que examinar este país constitui o "experimento mais seguro para obter conhecimento sobre a relação entre um país político e o pauperismo", justamente na Inglaterra em que a "penúria dos trabalhadores não é parcial, mas universal".

É desse caso concreto que Marx retira as determinações mais centrais do problema e que revelam os limites da atuação do Estado frente às contradições sociais no século XIX, mas nos permite apreender certa imanência geral do Estado capitalista. Nosso autor analisa as decisões parlamentares, as divergências políticas entre os partidos (um enxergando no outro as causas das mazelas sociais), materiais da economia política, relatórios médicos, debates públicos pela imprensa. A análise de realidade empreendida, que persegue e circula o nexo objetivo entre Estado e pauperismo, pôde revelar que se tentou na Inglaterra "acabar com o pauperismo por meio da beneficência e de medidas administrativas" sem encarar o "avanço progressivo do pauperismo como consequência necessária da indústria moderna" (MARX, 2010, p. 34-35).

Com a inspeção do caso inglês, é possível demonstrar que o combate à pobreza por meio das medidas administrativas (isto é, uma das facetas da administração política propriamente dita) é a conversão dos problemas sociais em objeto de administração, o que tem especial importância para a explicitação dos limites da própria administração política:

\footnotetext{
${ }^{15}$ A constante referência entre os teóricos da administração política à ideia de que a administração não é apenas técnica, mas, sobretudo, política (e.g. SANTOS et al., 2017, p. 956) nos traz para uma frágil posição em que se supõe que a razão política, por algum motivo nunca explicado, guarda alguma superioridade por si própria. É a mesma posição que precisa assumir a vontade política como determinante, como potência real, embora não seja mais do que vontade.
} 
[...] apesar das medidas administrativas, o pauperismo foi tomando a forma de uma instituição nacional, tomando-se, em consequência, inevitavelmente em objeto de uma administração ramificada e bastante ampla, uma administração que, todavia, não possui mais a incumbência de sufocá-lo, mas de discipliná-lo, de perpetuá-lo.

Essa administração desistiu de tentar estancar a fonte do pauperismo valendo-se de meios positivos; ela se restringe a cavar-lhe o túmulo, valendo-se da benevolência policial, toda vez que ele brota da superfície do país oficial. O Estado inglês, longe de ir além das medidas administrativas e beneficentes, retrocedeu aquém delas. Ele se restringe a administrar aquele pauperismo que, de tão desesperado, deixa-se apanhar e jogar na prisão [referência às Workhouses inglesas] (MARX, 2010, p. 35, grifos nossos).

O pauperismo precisa, pois, ser analisado em suas condições reais para a chegada à determinação de que o Estado não pode resolver tais contradições sem "suprimir a si próprio", disse Marx (2010, p. 39), precisamente em razão de estar assentado nessas contradições. As medidas administrativas, portanto, ou, o que é o mesmo, "a gestão do Estado" ("política pública+planejamento") - como preferem os teóricos da administração política -, não visa a superação das mazelas sociais. Administrá-las significa discipliná-las, preservá-las a níveis aceitáveis, toleráveis, em "certo nível de bem-estar", que não agucem os ânimos e nem despertem a ameaça de impulsos de mudanças efetivamente estruturais. É preciso dizer à administração política: De te fabula narratur!

A partir dessa análise de realidade, revela-se que a administração dos problemas sociais é o próprio limite do Estado que converte tais contradições em objetos de administração, pois "na medida em que os Estados se ocuparam com o pauperismo, restringiram-se às medidas administrativas e beneficentes ou retrocederam aquém da administração e da beneficência. O Estado pode agir de outro modo?” (MARX, 2010, p. 38).

O Estado do capital não pode agir de outro modo, pois não se revela ao próprio Estado as causações primárias dos problemas que supostamente combate. Em outras palavras, o “Estado jamais verá no 'Estado e na organização da sociedade' a razão das mazelas sociais" (MARX, 2010, p. 38). Está posto já o horizonte da razão política que possui um limite real, dadas as condições de possibilidade do próprio entendimento político. Vejamos primeiro tal limite real antes de retomarmos o limite daí derivado da razão política: 
O Estado não pode suprimir a contradição entre a finalidade e a boa vontade da administração, por um lado, e seus meios e sua capacidade, por outro, sem suprimir a si próprio, pois ele está baseado nessa contradição. Ele está baseado na contradição entre a vida pública e a vida privada, na contradição entre os interesses gerais e os interesses particulares. Em consequência, a administração deve restringir-se a uma atividade formal e negativa, porque o seu poder termina onde começa a vida burguesa e seu labor. Sim, frente às consequências decorrentes da natureza associal dessa vida burguesa, dessa propriedade privada, desse comércio, dessa indústria, dessa espoliação recíproca dos diversos círculos burgueses, frente a essas consequências a lei natural da administração é a impotência (MARX, 2010, p. 39, itálico no original).

Como o Estado tem por base as próprias contradições, depende delas e existe em relação a elas, a administração é impotente no sentido de sua superação. O limite da administração, portanto, é a perpetuação das contradições que são sua base. O impulso verdadeiramente transformador da realidade precisa ser externo ao Estado, nasce necessariamente externo a ele, tem alma social, mas o Estado mesmo não pode assumir essa sua impotência, da mesma forma que tal impotência não pode ser revelada pelo mainstream nem pela administração política que o combate. Em outros termos, o "Estado não pode, portanto, acreditar que a impotência seja inerente à sua administração, ou seja, a si mesmo. Ele pode tão somente admitir deficiências formais e casuais na mesma e tentar corrigi-las" (MARX, 2010, p. 40). Assim, os limites dessa atuação político-administrativa do Estado revelam-se não pela hipostasia de argumentos presos a pressupostos conceituais, não pelo valor mais ou menos heurístico de uma elaboração ideal, mas se ancoram nas determinações objetivas que a análise de realidade do caso concreto revela.

Agora podemos retomar a questão do entendimento político, da razão política, uma vez que já ficaram à mostra os limites objetivos que formam as condições de possibilidade para tal entendimento e ajudam a revelar como a corrente da administração política se move dentro desse entendimento e, portanto, também como uma formação ideal ou ideologia de tipo particular:

Quanto mais poderoso for o Estado, ou seja, quanto mais político for um país, tanto menos estará inclinado a buscar no princípio do Estado, ou seja, na atual organização da sociedade, da qual o Estado é 
expressão ativa, autoconsciente e oficial, a razão das mazelas sociais e a compreender seu princípio universal. O entendimento político é entendimento político justamente porque pensa dentro dos limites da política. Quanto mais aguçado, quanto mais ativo ele for, tanto menos capaz será de compreender mazelas sociais. [...]. O princípio da política é a vontade. Quanto mais unilateral, ou seja, quando mais bem-acabado for o entendimento político, tanto mais ele acredita na onipotência da vontade, tanto mais cego ele é para as limitações naturais e intelectuais da vontade, tomando-se, portanto, tanto menos capaz de desvendar a fonte das mazelas sociais (MARX, 2010, p. 4041).

Dado que o Estado não pode eliminar as contradições que são sua base sem eliminar a si mesmo, o entendimento político acerca dessas contradições não ultrapassa a própria política como força de superação dessas contradições. Mas a materialização dessa política se dá pela administração do Estado: vontade política e impotência da administração, eis o limite da razão política operante nas suas condições objetivas de possibilidade. Na administração política, portanto, a suposição da onipotência da vontade e a impotência real da gestão estão em giro eterno no interior dos próprios limites da política - e esta como expressão de desigualdade e dominação.

Cabe, portanto, um esforço de síntese. O entendimento político "pensa dentro dos limites da política" e a administração é irresolutiva das contradições que são a base do Estado, perpetuando-as como objetos de gestão. Uma razão que não desvenda a fonte das mazelas sociais implica medidas administrativas como limite da atuação, perpetuando as contradições que são seu pressuposto. No limite, atende aos interesses das classes dominantes por preservar no seio da sociedade uma dada distribuição dos meios de produção da riqueza, uma distribuição tomada como dada por tais medidas administrativas. Quando muito avançadas - como é o caso da propositura política da administração política, isto é, bem para além da repressão direta -, tais medidas administrativas encontram no sincretismo seu limite filosófico e nas políticas distributivistas no plano do consumo/circulação seu limite prático, deixando inteiramente intactas as contradições estruturais, pois supõe como necessária e sempre necessária uma acomodação dos antagonismos, nunca sua efetiva abolição ${ }^{16}$.

\footnotetext{
${ }^{16}$ Considere a limitação à dimensão da circulação quando se lê que os "problemas da Administração Política possuem um elevado grau de generalidade e abstração que consistem em responder às seguintes questões: Como devemos organizar o sistema produtivo de uma sociedade? Como os agentes econômicos agem dentro desse
} 
Com efeito, apenas a organização das massas e classes dominadas pode impor uma alteração real nas relações sociais de produção e, por decorrência, uma alteração na atuação do Estado frente a tais relações contraditórias no sentido de destruí-las (PAÇO CUNHA, 2016). Em suma, uma ação política nunca desconectada da luta econômica e que visa superar a própria política porque entrevê a necessária superação das contradições que formam sua base real. Isso é algo impossível para um "modelo de gestão das relações sociais", para a gestão do Estado partindo de si mesma e que toma as contradições como dadas, que não visa a sua própria superação como Estado e não está além de administrar tais contradições. E qual a razão para essa circunstância? Sobretudo porque a correlação de forças dos interesses da própria burocracia de Estado (gestores políticos do capital) e dos proprietários do poder econômico (e os gestores econômicos do capital) não põe e nem pode pôr como horizonte a descontinuidade das relações de produção e do próprio Estado capitalista. Assim, a administração política como ponto de vista do Estado paga tributo a essas dificuldades apontadas e precisa ir além de si mesma, explicitando as próprias contradições que lhe dão origem.

\section{IMPLICAÇÕES PARA A PESQUISA DA ADMINISTRAÇÃO POLÍTICA}

Com a ajuda dessas considerações ficam expostas problemáticas que a administração política enquanto movimento científico precisa enfrentar. A saída está apontada por uma aproximação com a crítica da economia política que possibilite uma crítica da própria administração política, o que redunda em uma fundamentação decisivamente materialista.

Nesse sentido, é importante reter que a categoria essencial da gestão do Estado são as contradições sociais e não a sua própria gestão. Esse é seu objeto real, efetivo, seus pressupostos convertidos em material de sua administração. Uma vez abandonada a centralidade da gestão, revelam-se as contradições ao fundo: a relação entre as classes, o problema da produção do valor, da propriedade sobre os meios de produção. Assim, o esforço científico não deve limitar-se ao plano da circulação e do consumo. Indo além desse nível da realidade, não significa dizer que as questões daí derivadas não tenham qualquer relevância. Entretanto, precisam revelar o nexo com o momento da produção, com os conflitos potencialmente engendrados em torno do como se dispor da apropriação do mais-trabalho. Abandonando esse nível mais profundo da realidade, o resultado é a reflexão limitada à

sistema? Qual a melhor forma para distribuir a riqueza produzida nesse sistema? Quem deve consumir a riqueza gerada por essa sociedade?" (SANTOS et al., 2014, p. 189). 
esfera da circulação da riqueza. Por isso, as medidas administrativas como materialização da gestão do Estado, como mostramos, toma a distribuição dos meios de produção como algo dado e acabado, como "lei natural". Aí se encontram um dos pontos a serem observados para a crítica da administração política: passar aos nexos objetivos por meio dos quais se move a realidade concreta e contraditória.

Ao depositar toda a energia na vontade política que não transcende os limites da própria política e na impotência da administração em anular as contradições, não se abandona o autogiro da razão política. Limitando-se à gestão do Estado, portanto, como angulação da realidade, perde-se de vista precisamente a real função do Estado capitalista e a relação desse aparato administrativo, jurídico e militar frente às contradições e classes sociais e, assume-se como virtude o vício do Estado sincrético que procura, parafraseando Marx (2013, p. 87), “conciliar o inconciliável".

Cientificamente, é preciso questionar o entendimento político dentro do qual vem se movendo a corrente teórica da administração política atualmente. Ora, se as condições objetivas revelam a obstrução da superação das contradições por meio de medidas administrativas, a insistência em permanecer circulando no interior do entendimento político revela uma dificuldade de apreensão dos nexos reais por meio dos quais se movem as próprias contradições. Nesse sentido, ser matrizada pela razão política é ser consequente a uma variante do politicismo:

[...] o politicismo arma uma política avessa, ou incapaz de levar em consideração os imperativos sociais e as determinantes econômicas. Expulsa a economia da política ou, no mínimo, torna o processo econômico meramente paralelo ou derivado do andamento político, sem nunca considerá-los em seus contínuos e indissolúveis entrelaçamentos reais, e jamais admitindo o caráter ontologicamente fundante e matrizador do econômico em relação ao político. Trata-se, está claro, de um passo ideológico de raiz liberal (CHASIN, 2000, p. 124, itálico no original).

Não queremos dizer que não existe consideração sobre a economia nos debates da administração política. Pelo contrário, encontra-se nisto, aliás, a base racional que falta em geral aos estudos organizacionais, conforme apontamos antes na introdução. O que há é um pressuposto de que a economia capitalista é um objeto de manipulação de acordo com uma vontade política que aparece sem mediação das classes sociais ou constrangimentos objetivos impostos pela dinâmica econômica. Os casos concretos aludidos, entretanto, dão conta de 
sugerir que não é o Estado o regulador autêntico do sistema. Seu princípio regulador é a lógica do capital $^{17}$. O Estado, resultante dos conflitos e acomodações de classes, como organizador de potência contingente, produz respostas à dinâmica econômica à qual condiciona muito parcialmente, resultando em efeitos não antecipados. $\mathrm{O}$ assim chamado “capitalismo organizado" entre 1945 e 1970, por exemplo, não foi um produto mecânico do Estado, operando medidas inflacionárias e distributivistas, senão uma resultante diante da ampla destruição e desvalorização de capital durante o período anterior e que tornou possível uma espiral expansiva do capital e também elevadas taxas de lucro com o verdadeiro auxílio dos Estados nacionais por meio de gastos militares dada a tensão internacional de disputa entre as potências de então (HARMAN, 1999) e de algum cerceamento aos movimentos trabalhistas nas economias centrais (BRENNER, 2006). As mesmas condições não foram reproduzíveis nos anos subsequentes a 1975, não por motivo de uma nova razão política neoliberal, mas por crescimento da composição orgânica do capital que, sem efeitos de outras forças contrárias, efetivou a baixa tendencial da taxa de lucro, promovendo medidas liberalizantes aos setores financeiros, favorecendo bolhas e crises econômicas nas décadas seguintes (KLIMAN, 2011; ROBERTS, 2016; PAÇO CUNHA, 2018).

Nessa direção, a análise dos casos concretos em que se relacionam a gestão do Estado e as contradições que formam sua base revela que, não obstante as diferenças, as medidas administrativas são o modo mais central de atuação do Estado ${ }^{18}$. Mas é a análise de realidade

\footnotetext{
${ }^{17}$ São inúmeras as provas de que a controlabilidade do sistema é muito parcial e contingente (MÉSZÁROS, 2002). Não só em razão de alcance variado dos Estados nacionais sobre a dinâmica global do capital, mas sobretudo pelas consequências dificilmente antecipadas de decisões no plano político. O caso da crise de 2008 , por exemplo, demonstra como a injeção, por parte do governo estadunidense, de muitos bilhões de dólares como salvaguarda de corporações produtivas e bancos evita a quebra de longas cadeias econômicas ainda que, em razão disso mesmo, cria obstáculos à uma recuperação mais rápida na medida em que limita a potencial desvalorização de capital que permitiria um patamar propício para novo ciclo de acumulação. Obviamente que não se pode derivar disso uma política deliberada de falências gerais, porquanto seja temerária a capacidade de efetivamente salvaguardar o sistema das consequências de um ponto tão rebaixado da espiral expansiva do capital.

${ }^{18}$ Isso não significa que não existam estudos de casos concretos no movimento da administração política. Ao contrário, há na verdade um esforço considerável nessa direção, como os anunciados acerca do Brasil e da Espanha entre 1930 e 1970 (RIBEIRO, 2008). Não obstante, persiste um tipo de tautologia. Compare a delimitação básica da "administração política" comentada antes - "forma pela qual o Estado se organiza e se estrutura para gerir o processo das relações sociais de produção" (SANTOS; RIBEIRO, 1993, p. 106) - com o achado do caso concreto: "a Administração Política assume uma perspectiva muito mais ampla e abstrata. Em síntese, entendemos que o modelo de Administração Política vigente entre os anos 30 e 70 compreende a forma pela qual o Estado se organizou e se estruturou para gestionar e executar o processo das relações sociais de produção, ou seja, para responder às novas funções econômicas e sociais - sua 'finalidade social'" (RIBEIRO, 2008, p. 17). A pesquisa dos casos concretos acaba encontrando aquilo que já é suposto, bastando inserir tais casos na delimitação básica da administração política. Em suma, não basta analisar o caso concreto; é preciso extrair o nexo real entre a gestão do Estado e as contradições sociais.
} 
dos casos concretos, seja do Brasil, dos Estados Unidos ou da Suécia, que revela tais questões, portanto, a impotência irresolutiva da administração. Assim, é imprescindível à administração política como movimento teórico, que pretende deixar o entendimento político e encaminhar uma reta crítica da própria administração política, realizar uma análise da realidade por meio daquilo que há de melhor quando o assunto é a reprodução dos nexos objetivos das contradições moventes: o materialismo que fundamenta a crítica da economia política.

Com efeito, o desenvolvimento da administração política depende, a nosso ver, de uma crítica da administração política. Depende, por isso, de uma apreensão materialista do Estado e das relações de classes sociais nos termos antes esboçados para transpor os limites da tradição ocidental de identificar no Estado um ente moral capaz de servir de mediação não contraditória. Precisa romper os limites da razão política e identificar o próprio Estado como índice dos problemas e não a mediação mais indicada para a solução. Nessa direção, depende de mais crítica da economia política e não menos.

Nessa direção, é possível deixar indicado, no espírito do primeiro parágrafo de nossa introdução, aquilo que a administração política expressa da realidade. $\mathrm{O}$ efetivo passo adiante do movimento teórico, quando a área de administração e o campo dos estudos organizacionais são as referências, sempre esteve no diálogo ainda que parcial com a crítica da economia política e no reconhecimento de que há uma intencionalidade de regulação consciente do sistema. Seja em tradição diretamente keynesiana, certamente muito forte na corrente em questão, seja em tradição ainda mais aderente às categorias da tradição marxista (AGLIETTA, 2015), o fato, no entanto, é que esse tema não pode ser considerado inteiramente novo.

No sentido de dar vasão ao meritório impulso de investigação realizado pela corrente teórica, é coerente reconhecer a angulação anteriormente apresentada de determinação da gestão do Estado como "esfera da administração política" de "políticas públicas + planejamento". Poder-se-ia chegar mais longe e considerar a existência de intencionalidade de regulação global do sistema por mediação de mecanismos que transcendem em parte os Estados nacionais. A pesquisa científica então estaria direcionada a estabelecer o nexo entre as medidas administrativas e as condições econômicas e sociais, avaliando a potência contingente (profundidade e duração dos efeitos) de tais medidas em casos concretos cuja variação não impede a explicitação da finalidade última de garantir as condições de reprodução ampliada do capital. Em uma retomada decisiva com a crítica da economia política, podemos apontar brevemente alguns fatores direcionadores preliminares: 
(i) O Estado, porquanto complexo político (administrativo, jurídico e militar), se efetiva como organizador dos interesses coletivos do capital - o que inclui os gestores políticos do capital (JUSTEN et al., 2017; PAÇO CUNHA; JORGE, 2018) - e, por isso mesmo, com porosidade relativa e contingente às demandas das classes dominadas por necessidade do próprio intuito de regulação do sistema. Sendo tal complexo, produz e efetiva respostas à dinâmica econômica com efetividade variada e consequências não antecipadas, podendo agravar ao invés de sanar certos problemas.

(ii) Essa dinâmica possui um regulador fundamental que forma o núcleo profundo da base econômica: a lógica expansiva do valor e seus obstáculos internos e externos como contradição em movimento, o que inclui as novas especificidades de valorização, dificuldades de realização, crises, conflitos classistas e geopolíticos. Sendo este o princípio regulador efetivo de controlabilidade contingente, apenas parcialmente se extrai resultados inteiramente planejados. A clareza com respeito ao princípio regulador revela igualmente o que a corrente teórica da administração política também alcançou: a necessidade de considerar as decisões no plano "profissional" o que, para nós, se expressa melhor como tarefas dos gestores do capital produtivo, financeiro e comercial de reprodução do capital (PAÇO CUNHA; JORGE, 2018).

(iii) As respostas do plano político (ou administração política) se realizam por meio de mecanismos repressivos e medidas administrativas, cuja relação histórica e movimento é determinada e determinante da própria dinâmica econômica e social em que esta é preponderante. Sobre uma mesma base de relações sociais de produção, tais meios (repressivos e administrativos) variam consideravelmente com protagonismos discutíveis nos casos concretos.

(iv) O estudo das medidas administrativas ("políticas públicas+planejamento") é incontornável, indo bem além de considerar "análise/avaliação mais conteudista e que só pode ser realizada em sua totalidade por meio do censo" (SANTOS et al., 2017, p. 954). É preciso considerar a real funcionalidade, sem ilusões, seus alcances e rebatimentos sobre o conflito classista no plano econômico e político, além dos alvos diretamente explícitos. É sobremaneira importante investigar as correlações de forças ex ante e ex post desenvolvimento de medidas administrativas delimitadas, sem abandonar o campo da hierarquização internacional entre economias nacionais e suas alianças. Estudos longitudinais, de 
corte histórico, são imprescindíveis. Desta consideração é que se torna possível extração de programa político-econômico, não sem antes um último fator.

(v) A necessária consideração sobre o "desenvolvimentismo como ideologia" e a “administração econômica capitalista das crises" além de, pelo menos, três de suas dimensões do "sistema de regulação" como "esforços em criar as condições para expansão do capital” (AMIN, 2014, p. 17): Fundo Monetário Internacional, Banco Mundial, Acordo Geral sobre Tarifas e Comércio/Organização Mundial do Comércio. A dinâmica do capital global implica complexidades que agravam a controlabilidade contingencial do sistema. De toda forma, para um capital global e seus modos operativos encontrados na articulação entre grandes corporações e Estados nacionais equivale um mercado mundial e os canais financeiros associados, quer dizer, a apreensão da dinâmica do capital total depende da determinação da produção e circulação do valor, incluindo suas formas irracionais como capital fictício (MARX, 2017).

Tais fatores direcionadores da pesquisa científica sobre a administração política apreendida nos termos explicitados devem ser levados à prova. O passo subsequente que deve ser tomado, de maneira contributiva, é proceder à análise de realidade detida nos problemas apresentados sem recuar na associação com a crítica da economia política e com o materialismo que a fundamenta.

\section{REFERÊNCIAS}

AGLIETTA, Michel. A theory of capitalist regulation: the US experience. Verso Books, 2015.

AMIN, Samir. Capitalism in the age of globalization: the management of contemporary society. London: Zed Books, 2014.

BRENNER, Robert. The economics of global turbulence: the advanced capitalist economies from long boom to long downturn, 1945-2005. Verso, 2006.

CHASIN, J. Conquistar a democracia pela base. In: A miséria brasileira: 1964 - 1994: do golpe militar à crise social. São Paulo: Estudos e Edições Ad Hominem, 2000, p. 59-78.

DRUCKER, P. F. O novo papel da administração. São Paulo: Nova Cultural, 1986. FONSECA, F. A Administração Política: em busca de uma teoria crítica da Administração Pública. Revista Brasileira de Administração Política. vol 1, n. 1, p, 7-9, 2008. 
GOMES, F.G. O jovem percurso da administração política. Revista de Administração Pública. v. 46, n. 1, p. 7-24, 2012.

GUEDES, L. T. A relação entre ciência e ideologia na crítica da administração política. VI Encontro de Administração Política. Niterói, 2015.

JUSTEN, A., GURGEL. C. R. M., FERRAZ, D. L. S., \& PAÇO-CUNHA, E. Administração política: por uma agenda de pesquisa marxista. Farol - Revista de Estudos Organizacionais e Sociedade, v. 4, n. 10, p. 663-759, 2017.

HARMAN, Chris. Explaining the crisis. London: Bookmarks, 1999.

HEGEL, G. W. F. Filosofia do direito. São Leopoldo: Unisinos, 2010.

KAHN, Herman. O futuro da empresa. São Paulo: Melhoramentos, 1975.

KLIMAN, Andrew. The failure of capitalist production: underlying causes of the great recession. Pluto Press, 2011.

LUKÁCS, G. Para uma ontologia do ser social. São Paulo: Boitempo, 2013.

MARX, K; Engels, F. Manifesto do Partido Comunista. São Paulo: Boitempo, 1998.

MARX, K. Crítica da filosofia do direito de Hegel. São Paulo: Boitempo, 2005.

MARX, K. Glosas críticas ao artigo “'O rei da Prússia e a reforma social'. De um prussiano". In: Lutas de classes na Alemanha. São Paulo: Boitempo, 2010.

MARX, K. O capital. v. 1. São Paulo: Boitempo, 2013.

MARX, K. O capital. v. 3. São Paulo: Boitempo, 2017.

MÉSZÁROS, I. Para além do capital. São Paulo: Boitempo, 2002.

PAÇO CUNHA, E. Gênese, razoabilidade e formas mistificadas da relação social de

produção em Marx: a organização burocrática como abstração arbitrária. (Tese de

Doutorado), CEPEAD/UFMG, 2010.

PAÇO CUNHA, E. Que fazer da burocracia de estado? Do indiferentismo às reciprocidades.

Administração Pública e Gestão Social, v. 8, n. 1, p.. 15-26, 2016.

PAÇO CUNHA, E. Movimento real da forma política em Marx: elementos para a crítica dos 'aparelhos repressivos' como síntese do Estado capitalista PAÇO CUNHA, E. Movimento real da forma política em Marx: elementos para a crítica dos 'aparelhos repressivos' como síntese do Estado capitalista. Revista Marx e o Marxismo. Niterói, v.4. n..7, p. 201-233, 2017.

PAÇO CUNHA, E; GUEDES, L. T. Recepções do ideário marxista pelo pensamento administrativo: da oposição indireta à assimilação relativa. Organizações \& Sociedade, v. 24, n. 82, p. 432-455, 2017. 
PAÇO-CUNHA, E. Chasin e Mészáros: a propósito da assim chamada crise estrutural. São Paulo: Anuário Lukács 2018, p. 155-185, 2018.

PAÇO CUNHA, E; JORGE, T. M. Personificações do Capital e Longa Depressão nos

Estados Unidos: Contribuições de Robert Brenner para o Estudo dos Gestores do Capital no Contexto de Crise. XLII Encontro da ANPAD, EnANPAD 2018, Curitiba, 2018.

PIKETTY, T. O capital no século XXI. Rio de Janeiro: Intrínseca, 2014.

POULANTZAS, N. O estado, o poder, o socialismo. São Paulo: Graal, 1980.

RIBEIRO, E.M. Revisitando o conceito de administração política. Revista Brasileira de

Administração Política. vol. 1, n. 1, p. 11-22, 2008.

ROBERTS, Michael. The long depression. Chicago: Haymarket Books, 2016.

SANTOS, R.S; RIBEIRO, E.M. A administração política brasileira. Revista de

Administração Pública, v. 27, n. 4, p. 102-135, 1993.

SANTOS, R.S. A administração política como campo do conhecimento. $2^{\mathrm{a}}$ ed. Salvador: FEA UFBA; São Paulo: Hucitec-Mandacary, 2009.

SANTOS, E. L.; Santana, WESLEI, G. P; SANTOS, R. S; BRAGA, V. L. Contribuições da administração política para o campo da administração. Revista Interdisciplinar de Gestão Social, v. 3, n. 2,p. 105-126, 2014.

SANTOS, R. S. et al . A crise, o Estado e os equívocos da administração política do capitalismo contemporâneo. Cad. EBAPE.BR, v. 14, n. 4, p. 1011-1034, 2016.

SANTOS, R. S.et al . Administração política e políticas públicas: em busca de uma nova abordagem teórico-metodológica para a (re)interpretação das relações sociais de produção, circulação e distribuição. Cad. EBAPE.BR, v. 15, n. 4, p. 939-959, 2017 . 